\title{
Winning the Baldrige Award How the Henry Ford Health System Undertook a Five-Year Improvement Process
}

\section{Gannon O’Reilly, Brooke Dziurman, Jordan Sprague, Michael D. Witt}

\author{
University of Michigan-Flint
}

Henry Ford Health Systems (HFHS) won the 2011 Baldrige Award, a major accomplishment. This achievement resulted from a systemwide focus on minimizing and controlling medical errors, a cultural shift to stimulate innovation and creative problem solving, and service excellence at every level. The fiveyear effort centered on meeting Baldrige Award criteria, typically utilized in the for-profit setting. When applied to the nomprofit sector, HFHS managed to reduce costs, reduce medication and treatment errors, introduce multiple creative clinical programs, and launch a new Ritz Carlton-quality, hotel-style service.

Keywords: health, innovation, leadership, management

\} Nitiated By THE White House through the Department of Commerce, the Malcolm Baldrige National Quality Award acknowledges the highest level of performance excellence for any business within the United States, for-profit and nonprofit alike. Xerox, Ritz-Carlton, and Boeing are among some of the most notable past awardees. Today, the Henry Ford Health System (HFHS) can list itself among them as the recipient of the 2011 Malcolm

Correspondence to: Michael D. Witt, University of Michigan-Flint, School of Management, 303 E. Kearsley St., Riverfront Place, Flint, MI 48433. E-mail: mdwitt@umflint.edu 


\section{HFHS sought clarity by going back to basics: quality, responsive care with a "zero- defect" attitude.}

Baldrige Award-a significant accomplishment for any organization, and particularly for a health care provider.

Congress passed the Malcolm Baldrige National Quality Improvement Act in 1987; the act established the Baldrige Award and reflected the increasing demands of the global market and the growing importance of defining and disseminating best practices. The idea of the act and accompanying award is to improve the competitiveness of U.S. organizations by establishing a target set of performance "excellence" criteria. The criteria of the Baldrige Award present a framework devised to improve overall organizational performance, with seven categories: leadership, strategic planning, customer focus, measurement/analysis/knowledge management, workforce focus, operations focus, and results. In effect, these constitute a roadmap for companies to follow.

Jim Collins, best-selling author of Good to Great: Why Some Companies Make the Leap . . . and Others Don't, may have said it best: "I see the Baldrige process as a powerful set of mechanisms for disciplined people engaged in disciplined thought and taking disciplined action to create great organizations that produce exceptional results."

\section{Henry Ford Health Systems}

Henry Ford Health Systems is a large nonprofit health care facility in Detroit, Michigan. Following the Baldrige criteria, HFHS focused on best practices for reducing patient adverse incidents, enhancing service quality, and stimulating innovative thinking in improving quality and reducing costs. This was a good fit for HFHS because of its history in Detroit, a city with a long and celebrated history of entrepreneurship and achievement on a grand scale. How it accomplished this feat and the teaching lessons that can be gleaned from its success is the subject of this article.

In the first decade of the new millennium-years full of rapid change and technological disruption-HFHS sought clarity by going back to basics: quality, responsive care with a "zero-defect" attitude. It is not surprising that this health system in particular would adopt such an approach-HFHS was founded in 1915 by automotive pioneer Henry Ford, one of our nation's premier innovation and efficiency experts. The original facility was established as a forty-eight-bed facility in Detroit catering to the needs of the autoworkers. Many of the efficiency concepts seen in the auto industry have had an influence on the HFHS approach, perhaps attenuated, but nonetheless a factor in its resultant success.

Over the years HFHS evolved into a large integrated health care institution, fueled by auto employees with generous health care reimbursement benefits. It now competes with all health care providers in an increasingly competitive marketplace. HFHS handles 3.3 million patient visits annually, owns and operates seven hospitals, employs 
24,322 people, and had more than \$4 billion in revenues in 2011 . The hospitals include a large level-1 trauma flagship hospital, four community hospitals, and two psychiatric facilities. HFHS also operates thirty-three multispecialty ambulatory care centers, ninety-one community care operations and a wholly owned subsidiary insurance company, Health Alliance Plan (HAP). In its catchment area, HFHS protects a market share of 20 percent for acute care and 10 percent for ambulatory care. It plans to go live with a Medicaid health maintenance organization (HMO) in 2014.

HAP accounts for one-quarter of the HFHS patient-revenue, and $\$ 1.7$ billion in annual revenue. It was acquired in 1979 and is increasingly important to HFHS' success. HAP serves 545,000 individuals and 1,200 employer groups through $\mathrm{HMO}$, paid provider organization (PPO), and Medicare plans offering individual, group, and consumer-directed insurance products.

\section{The Baldrige Beginning}

Nancy Schlicting, chief executive officer (CEO) of HFHS, readily admits the company faced some serious challenges during the early 1990s. Former CEO, Gail Warden, had been forced to make some drastic changes in an attempt to make the company more performance based. The early 2000s brought about some of those changes with the replacement of the chief financial officer and human resource officer, along with the CEO transition, from Warden to Schlicting, that occurred in 2003. Schlicting recalls a conversation she had with Bill Conway, M.D., Henry Ford's chief quality officer, when she bluntly expressed her concerns: ". . . The operations here are horrible!" With fragmented, high-cost service delivery, financial losses due to unreimbursed care, and suburban patients unwilling to go downtown, the need for low-cost and high-quality care was apparent, as was the need for framework to get there. Determined to make a difference, Schlicting brought in an outside consulting firm, engaged former Baldrige awardees from Boeing, and made all quality issues public knowledge-and so the journey to the Baldrige Award began.

The application process for the Malcolm Baldrige Award is extensive, competitive, and intentionally unambiguous. Schlicting poignantly describes the endeavor as "daunting." The Baldrige Award is more than an accolade of success for HFHS- the Baldrige criteria played a crucial role in shaping HFHS' performance-based approach. "We used the [Baldrige] framework as the driving force . . . to set goals in all departments," says Schlicting. Improvements occurred rapidly after the initiative was embraced in 2004-05. Five application attempts were made before the efforts were recognized.

Three of HFHS' most impressive initiatives are discussed here in some detail: the No Harm Campaign, the Quality Expo, and the 5 


HFHS adopted a
proactive and
transparent
approach in 2007
with its No Harm
Campaign, a
program to
combat medical
mistakes.

Star Service Quality initiatives. Individually, they seem clever and useful; taken together, they reflect a patient-oriented, systemwide strategy to reduce errors and improve quality.

\section{Above All Else, Do No Harm}

HFHS adopted a proactive and transparent approach in 2007 with its No Harm Campaign, a program to combat medical mistakes. CEO Schlicting said, "Our No Harm Campaign focuses on enhancing our culture of safety, improving communications among care teams, and identifying causes of harm and redesigning care to eliminate them."

The No Harm Campaign was inspired by the Institute of Medicine's 1999 report that suggested up to 98,000 deaths each year are caused by medical errors. The campaign began with the identification and categorization of the major causes of harm: infection-related harm, procedure-related harm, medication-related harm, and other preventable harm. A systematic process of defining, measuring, collecting data, and analyzing specific harm events was developed. The process was led by clinicians and tested in pilot programs at the unit level. Successful initiatives were taken systemwide after they were tested, verified, refined, and standardized. The results of the programs were measured and organized by harm category, date aggregated, and made available to all stakeholders ("Eliminating Harm" 2012).

Indeed, the resultant statistics are impressive. From 2008 to 2010 the following were achieved: a 29 percent reduction in infectionrelated harms; 50 percent reduction in catheter-related bloodstream infections; 4 percent reduction in medication-related harm; 26 percent reduction in falls-related harm; and a 5.3 percent reduction in pressure ulcer-related harm. Combined inpatient harms decreased 26 percent from 2008 to 2011 , at a rate of 337 harm events per month ("HHS Secretary" 2012).

Additionally, employees are trained to understand those human limitations that contribute to error and are encouraged to speak up about safety concerns. A Safety Champion Program, in which 350 trained experts are dispersed throughout the system, serving as advocates for the various safety initiatives, facilitates this. The HFHS 2010 Employee Survey showed that employee engagement scores and culture of safety scores were substantially higher in units with the program. Schlicting set a lofty goal for HFHS: "to reduce harm events throughout our health system by 50 percent by 2013" (Conway 2011).

\section{Striving for Innovation: The Quality Expo}

Since 1991, HFHS has held an annual Quality Exposition, the purpose of which is to reward employees and departments for successful new quality initiatives, all focused on clinical innovations. Each department follows a set of guiding principles but has considerable 
flexibility in pursuing new ideas. According to Dr. Carolyn Clancy, director of the HFHS Agency for HealthCare Research and Quality, the program and the expo create an environment that is conducive to innovation and bursting with entrepreneurial spirit. Clancy explains, "The Quality Expo shows a real commitment to quality because people are taking the same general principles about defining the problems, assessing them, and then trying to improve . . . but applying them in a very diverse setting and celebrating with each other ..." (Annual Quality Exposition 2011).

A project entitled "Cancer Prevention and Treatment Disparity" (CPTD) won the 2010 expo. The CPTD objective was to improve the process for cancer screening and treatment for minorities and to facilitate equity in cancer screening rates. The staff attempted to remove barriers to care by improving community outreach, patient recruitment, and health literacy. Specifically, CPTD: improved educational literature by including more cultural and age appropriate content; changed recruitment efforts (of letter and telephone campaigns) to cash incentives, fruit smoothies, and month-end lunch offers (when Social Security money was low); and removed transportation barriers by waiving parking fees and providing taxi and bus fare (Gifford 2010).

CPTD was a success. Recruitment went from 8.3 percent return on effort (with the letter and phone campaign) to 51 percent and 92 percent, respectively, return on effort with the new approach. The screened recruits also saw lower emergency room visits and admissions, lower average lengths of stay (LOS), and higher revenues than matched controls. The outreach improvements increased patient engagement-particularly with the Medicaid-insured population who were not utilizing covered services. The strategies used in this project are transferable to other outreach efforts, such as in the senior citizen community, for which HFHS plans to take a similar route (Gifford 2010).

The 2011 expo featured a number of interesting projects, each broadly designed to improve care quality:

- Combat childhood obesity through an after-school program focused on helping children and families improve nutrition choices, increase physical activity, improve self-esteem, and reduce health risks and chronic conditions associated with being overweight.

- Reduce influenza by increasing vaccination compliance and, through education and innovation, reduce the risk of employees, patients, and visitors spreading the flu.

- Make medication management more efficient for patients and health care professionals by adding a clinical pharmacist to the primary care team.

- Improve turnaround time in delivering patients' mammogram results.

- Improve multilingual communication by providing limited English speakers with videotapes to better explain pain control options and the consent process at the time of labor and delivery (Dolan 2011). 


\section{HFHS'}

progressive

approach to

customer service

has led it to

build a $\$ 360$

million dollar

state-of-the-art

facility in West

Bloomfield,

Michigan.
Over the years, the Quality Expo has become important to HFHS management, beyond what would normally be expected of an employee recognition program. It provides an organized method to encourage and test ideas and to bring useful ones to fruition.

The Quality Expo is consciously inculcating a culture of change. The result makes implementing new organizational measures significantly easier. One such change began in 2005 when HFHS' wholly owned subsidiary insurance company, Health Alliance Plan, piloted an electronic prescription initiative at the request of the Big Three automakers: General Motors, Ford, and DaimlerChrysler. E-prescribing was quickly integrated systemwide. "In virtually every way health care quality and costs can be measured, the benefits of e-prescribing are compelling," said Francine Parker, HAP president and CEO, "E-Prescribing creates a seamless electronic path from the doctor, to the pharmacist, to the patient. We at HAP are proud to be involved as a catalyst and pacesetter in a collaborative program that already is proving its worth to members and patients, providers and employers." HFHS physicians now write more than 20,000 electronic prescriptions every week. Although not a direct result of the expo, it is doubtful such measures would be as quickly or easily embraced without such an environment.

\section{Star Customer Service}

HFHS' progressive approach to customer service has led it to build a $\$ 360$ million dollar state-of-the-art facility in West Bloomfield, Michigan. It opened in 2009, ". . . the first hospital we had built since 1915," says Nancy Schlichting, "Our other hospitals joined the system through acquisition. So we kept pushing: What is going to distinguish this hospital? What could we do that was unique and transformational? This had to be an exceptional place." And exceptional it is-private rooms, concierge services, an assortment of shops, fine dining, an atrium, and an overall prioritization of comfort and luxury (Taylor 2012).

The new facility's CEO, Gerard Van Grinsven, earned his degree in hotel management and enjoyed an impressive career as vice president of food and beverage at Ritz-Carlton before joining HFHS. Van Grinsven's involvement with HFHS began prior to the West Bloomfield location, and in many ways he was the catalyst for Henry Ford hospitals taking cues from the hospitality industry. "When you visit the café, or order from room service, we want you to say, 'I never thought hospital food could be like this.' When you're in your room, a concierge talks to you and your family: 'Do we need to do some shopping for you? Do we need to take care of any laundry?' We have high tea in the atrium every afternoon. These [amenities] cost almost nothing to create, yet they create a tremendous impression for everyone who encounters them," says Van Grinsven (Taylor 2012). 
Ritz-Carlton-inspired service can raise questions about cost, sustainability, and how this over-the-top luxury fits into the vision of quality excellence. HFHS leaders maintain that behind the seeming luxury is a strategic plan to reduce health care costs and further promote its organizational goals. The private rooms, for instance, by design reduce infection rates. By focusing on an enhanced level of service and patient communication, malpractice-related expenses are reduced (Hickson 2002). HFHS experienced this during the past decade, successfully reducing its medical malpractice expenses 62 percent to $\$ 17$ million in 2009 from $\$ 45$ million in 2001, even with patient volume increasing by 25 percent. Having a world-class level of service, HFHS leaders believe, will attract wealthier, private-pay patients, increase physician referrals, and improve staff satisfaction.

It remains to be seen whether HFHS' premium level of service in its West Bloomfield facility will translate into long-term sustainability. Based on the results thus far, evening symphonies in the atrium and day spa treatments may cease to be indulgences and become necessities for modern health care facilities.

Henry Ford Health Systems, guided by the actionable and measurable criteria of the Baldrige Award, achieved impressive outcomes:

1. The No Harm Campaign resulted in a drop in the overall harm rate of 24 percent in three years, with the next comparable health care organization seeing only a 6 percent decrease in the same period.

2. The Quality Expo, a mecca of innovation, allowed HFHS to capitalize on diverse ideas and promote internal engagement, the results of which brought about numerous improvements.

3. The unique emphasis on customer service has sharply decreased malpractice expenses during a period of exponential growth.

These organizational improvements have directly translated into a strong financial performance. In 2001 HFHS suffered operating losses, but since adopting the Baldrige framework its revenues have increased over the past eight years.

The Malcolm Baldrige National Quality Award provided both the game plan and the trophy for HFHS. Creatively implemented, the playbook successfully led HFHS down a path of improvement to prosperity. With HFHS' track record of successes in reducing errors, improving clinical care quality, focus on continuing improvement, innovation, cost efficiency, and patient satisfaction, it is well positioned to continue to build on the achievements that led to the Baldrige Award.

\section{References}

Annual Quality Exposition at Henry Ford Hospital and Health System. 2011. HenryFordTV, April 7. http://www.youtube.com /watch?v=OgLgshhoM0s. 
Baldrige Performance Excellence Program. 2009. "2011-2012 Health Care Criteria for Performance Excellence." http://www .nist.gov/baldrige/publications/upload/2011_2012_Health_Care _Criteria.pdf.

Conway, William A. 2011. "No Harm Campaign Improves Quality and Saves Lives." Quality Digest. December 12. http://www .qualitydigest.com/inside/health-care-article/no-harm-campaign -improves-quality-and-saves-lives.html\#.

Dolan, Megan. 2011. "Quality Expo: 20 Years of Healthcare Innovations." Henry Ford Health Systems. http://www.henryford $. \operatorname{com} /$ body.cfm? $\mathrm{id}=46335 \&$ action $=$ detail\&ref $=169$.

Dwight, Angell. 2006. "HAP, Henry Ford Health System e-Prescribing Technology Hits 500,000 'Scripts." Henry Ford Health Systems. http://www.henryford.com/body.cfm?id=46335\& action $=$ detail\&ref $=560$.

"Eliminating Harm in a Large, Integrated System." 2012. HPOE Case Study: Hospitals in Pursuit of Excellence. March 11. http:// www.hpoe.org/case-studies/626000808.

Gifford, Linda. 2010. "Cancer Prevention and Treatment: Overcoming Barriers to Care." Henry Ford Health Systems. Josephine Ford Cancer Center. http://www.henryford.com/body $. c f m ? \mathrm{id}=54560$.

Glenn, Rose. 2011. "Malcolm Baldrige National Quality Award." National Institute of Standards and Technology. http://www.nist.gov /baldrige/award_recipients/ford_profile.cfm.

Henry Ford Health Systems. "2011 Malcolm Baldrige National Quality Award Application."

"HHS Secretary Kathleen Sebelius Visits Henry Ford Hospital." 2012. Henry Ford Health System. http://www.henryford.com /body.cfm?id=55974.

Hickson, Gerald B. 2002. "Patient Complaints and Malpractice Risk." Journal of the American Medical Association. http://jama .ama-assn.org/content/287/22/2951.full.

McCarthy, Douglas. 2009. "Henry Ford Health System: A Framework for System Integration, Coordination, Collaboration, and Innovation." Commonwealth Fund. http://mobile. commonwealthfund.org/ /media/Files/Publications/Case Study/2009/Aug/1308_McCarthy_Henry_Ford_case_study.pdf.

Schlichting, Nancy. 2012. Personal interview, February 16.

Taylor, William C. 2012. "What Hospitals Can Learn from the Ritz." CNNMoney. Fortune. March 2. http://management.fortune.cnn .com/2011/03/02/what-hospitals-can-learn-from-the-ritz/. 
GANNON O'REILLY is a graduate of the University of Michigan-Flint School of Management.

Brooke DzIURman is a graduate of the University of Michigan-Flint School of Management.

JORDAN SPRAGUE is a graduate of the University of Michigan-Flint School of Management.

Michael D. WitT is a health care attorney, faculty member, and entrepreneur in residence at the University of Michigan-Flint School of Management. 